\title{
Molecular detection of pathogens in ticks and fleas collected from companion dogs and cats in East and Southeast Asia
}

\author{
Viet-Linh Nguyen ${ }^{1}$, Vito Colella ${ }^{1,2}$, Grazia Greco ${ }^{1}$, Fang Fang ${ }^{3}$, Wisnu Nurcahyo ${ }^{4}$, Upik Kesumawati Hadi ${ }^{5}$, \\ Virginia Venturina ${ }^{6}$, Kenneth Boon Yew Tong ${ }^{7}$, Yi-Lun Tsai ${ }^{8}$, Piyanan Taweethavonsawat ${ }^{9}$, \\ Saruda Tiwananthagorn ${ }^{10}$, Sahatchai Tangtrongsup ${ }^{10}$, Thong Quang Le ${ }^{11}$, Khanh Linh Buil ${ }^{12}$, Thom Do ${ }^{13}$, \\ Malaika Watanabe ${ }^{14}$, Puteri Azaziah Megat Abd Rani ${ }^{14}$, Filipe Dantas-Torres ${ }^{1,15}$, Lenaig Halos ${ }^{16}$, \\ Frederic Beugnet ${ }^{16}$ and Domenico Otranto ${ }^{1,17^{*}}$ (1)
}

\begin{abstract}
Background: Ticks and fleas are considered amongst the most important arthropod vectors of medical and veterinary concern due to their ability to transmit pathogens to a range of animal species including dogs, cats and humans. By sharing a common environment with humans, companion animal-associated parasitic arthropods may potentially transmit zoonotic vector-borne pathogens (VBPs). This study aimed to molecularly detect pathogens from ticks and fleas from companion dogs and cats in East and Southeast Asia.
\end{abstract}

Methods: A total of 392 ticks and 248 fleas were collected from 401 infested animals (i.e. 271 dogs and 130 cats) from China, Taiwan, Indonesia, Malaysia, Singapore, Thailand, the Philippines and Vietnam, and molecularly screened for the presence of pathogens. Ticks were tested for Rickettsia spp., Anaplasma spp., Ehrlichia spp., Babesia spp. and Hepatozoon spp. while fleas were screened for the presence of Rickettsia spp. and Bartonella spp.

Result: Of the 392 ticks tested, 37 (9.4\%) scored positive for at least one pathogen with Hepatozoon canis being the most prevalent (5.4\%), followed by Ehrlichia canis (1.8\%), Babesia vogeli (1\%), Anaplasma platys (0.8\%) and Rickettsia spp. (1\%) [including Rickettsia sp. (0.5\%), Rickettsia asembonensis (0.3\%) and Rickettsia felis (0.3\%)]. Out of 248 fleas tested, 106 (42.7\%) were harboring at least one pathogen with $R$. felis being the most common (19.4\%), followed by Bartonella spp. (16.5\%), Rickettsia asembonensis (10.9\%) and "Candidatus Rickettsia senegalensis" (0.4\%). Furthermore, 35 Rhipicephalus sanguineus ticks were subjected to phylogenetic analysis, of which 34 ticks belonged to the tropical and only one belonged to the temperate lineage (Rh. sanguineus (sensu stricto)).

Conclusion: Keywords: Ticks, Fleas, Dogs, Cats, Companion animals, Asia, Vector-borne pathogens, Zoonotic

*Correspondence: domenico.otranto@uniba.it

1 Dipartimento di Medicina Veterinaria, Università degli Studi di Bari, Bari, Italy

Full list of author information is available at the end of the article

\begin{abstract}
Background
Vector-borne diseases are caused by bacteria, viruses, protozoa and helminths transmitted by arthropod vectors, including ticks and fleas, worldwide [1]. For instance, Rhipicephalus sanguineus (sensu lato) ticks play an important role in the transmission of many pathogens to dogs (e.g. Ehrlichia canis, Rickettsia conorii, Rickettsii rickettsia, Babesia vogeli and Hepatozoon canis), some of
\end{abstract}

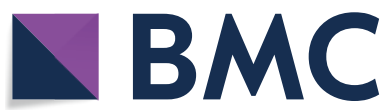

(c) The Author(s) 2020. This article is licensed under a Creative Commons Attribution 4.0 International License, which permits use, sharing, adaptation, distribution and reproduction in any medium or format, as long as you give appropriate credit to the original author(s) and the source, provide a link to the Creative Commons licence, and indicate if changes were made. The images or other third party material in this article are included in the article's Creative Commons licence, unless indicated otherwise in a credit line to the material. If material is not included in the article's Creative Commons licence and your intended use is not permitted by statutory regulation or exceeds the permitted use, you will need to obtain permission directly from the copyright holder. To view a copy of this licence, visit http://creativeco mmons.org/licenses/by/4.0/. The Creative Commons Public Domain Dedication waiver (http://creativecommons.org/publicdomain/ zero/1.0/) applies to the data made available in this article, unless otherwise stated in a credit line to the data. 
which may also infect humans [2-4]. The cat flea Ctenocephalides felis is the primary vector of Bartonella henselae, the main causative agent of cat-scratch disease [5,6], and is also considered as vector of Rickettsia felis [7].

East (EA) and Southeast Asia (SEA) are among the world's fastest-growing economic regions [8], which also resulted in a rise in the number of companion dogs and cats [9]. Companion dogs and cats live in close association with humans, potentially carrying ticks and fleas into human settlements. A large-scale survey conducted in EA and SEA reported that $22.3 \%$ of dogs and $3.7 \%$ of cats were infested by ticks, while $14.8 \%$ of dogs and $19.6 \%$ of cats were infested by fleas [10]. The most common flea species parasitizing dogs and cats in EA and SEA is C. felis, with Ctenocephalides orientis being increasingly observed in dogs $[10,11]$. Rhipicephalus sanguineus (s.l.), Rhipicephalus haemaphysaloides and Haemaphysalis longicornis represent the most common tick species reported in dogs and cats [10-14]. These tick species are responsible for the transmission of several species of apicomplexan protozoa of the genus Babesia. Babesia vogeli was reported in cats in Thailand and China $[15,16]$ and widely reported in dogs in EA and SEA, including China, Cambodia, Thailand, the Philippines and Malaysia [17-20]. Additionally, dogs from Taiwan, Malaysia, China, and Singapore [10, 21, 22] were also diagnosed with Babesia gibsoni infection. Other apicomplexan parasite commonly found in dogs across this region is $H$. canis, which is transmitted by ingestion of Rh. sanguineus (s.l.). This protozoan is commonly found in dogs from Thailand, Taiwan, China, Cambodia, Malaysia, Vietnam and the Philippines [10, $17,18,23-26]$ and in cats from Thailand and the Philippines $[10,24]$. Of the tick-borne anaplasmataceae bacteria, Anaplasma platys was found in dogs from Malaysia [22] and cats from Thailand [27]. Apart from tick-borne pathogens, flea-borne pathogens are also increasingly recognized as important pathogenic agents to animals and humans. For instance, $R$. felis, the etiological agent of flea-borne spotted fever in humans, has been detected in dogs from Cambodia and China $[18,28]$ and in C. felis from Taiwan, Laos, and Malaysia [29, 30]. Other zoonotic flea-borne pathogens such as $B$. henselae and Bartonella clarridgeiae, agents of cat-scratch disease, were molecularly detected in cats and their fleas from the Philippines, Indonesia, Singapore, Thailand, Malaysia and China with the prevalence ranging from 10 to $60 \%$ [31-36].

Despite previous scientific investigations reported the circulation of vector-borne pathogens (VBPs) in dogs and cats in EA and SEA, there is a lack of similar studies conducted in their associated ticks and fleas. Therefore, the present study aimed to provide an overview of the pathogens circulating in ticks and fleas from companion dogs and cats in EA and SEA.

\section{Methods}

Samples collection and DNA isolation

Of the 2381 privately-owned animals examined (i.e. 1229 dogs and 1152 cats), ticks and fleas were collected from 401 infested animals (i.e. 271 dogs and 130 cats) from China, Taiwan, Indonesia, Malaysia, Singapore, Thailand, the Philippines and Vietnam under the context of a previous multicenter survey [10]. Ticks and fleas were collected and placed in labelled tubes individualized per host, containing $70 \%$ ethanol. Ticks and fleas $(20 \%)$ were randomly selected from each tick/flea species and from each infested animal in all studied countries, giving a total number of 392 ticks (i.e. 377 Rh. sanguineus (s.l.), 3 Rh. haemaphysaloides, 7 H. longicornis, 2 Haemaphysalis wellingtoni, 1 Haemaphysalis hystricis, 1 Haemaphysalis campanulata and 1 Ixodes sp.) from 248 animals (39 cats and 209 dogs) and 248 fleas (i.e. 209 C. felis, 38 C. orientis and 1 Xenopsylla cheopis) from 213 animals (104 cats and 109 dogs) were subjected to DNA isolation individually. Data on the molecular identification of these ticks and fleas are available elsewhere (see Table 4 in Colella et al. [10]) Genomic DNA was isolated according to the procedures previously described [10,37].

\section{Molecular detection and phylogenetic analysis of pathogens}

Tick DNA samples were tested for the presence of apicomplexan protozoa (i.e. Babesia spp., Hepatozoon spp.), Anaplasmataceae (i.e. Anaplasma spp., Ehrlichia spp.) and Coxiella burnetii by conventional PCR (cPCR). Flea DNA samples were tested by using real-time PCR for Bartonella spp. The presence of Rickettsia spp. was also screened in both tick and flea samples. In particular, the first cPCR amplified a portion of citrate synthase ( $g l t A)$ gene, which is presented in all members of the genus Rickettsia. Positive samples were then subjected to a second cPCR, which amplified a fragment of the outer membrane protein (ompA) of the spotted fever group (SFG) rickettsiae. All primers and PCR protocols used for the detection of VBPs are summarized in Table 1. For all reactions, DNA of pathogen-positive samples served as a positive control. Amplified CPCR products were examined on $2 \%$ agarose gels stained with GelRed (VWR International PBI, Milan, Italy) and visualized on a GelLogic 100 gel documentation system (Kodak, New York, USA). The cPCR amplicons were sequenced using the Big Dye Terminator v.3.1 chemistry in a 3130 Genetic analyzer (Applied Biosystems, California, USA). Nucleotide sequences were edited, aligned and analyzed using the BioEdit 7.0 software and compared with those available 
Table 1 Primers, target genes and PCR conditions used in this study

\begin{tabular}{|c|c|c|c|c|c|}
\hline Pathogen & Primer $\left(5^{\prime}-3^{\prime}\right)$ & Target gene & $\begin{array}{l}\text { Product } \\
\text { size }(b p)\end{array}$ & PCR protocol & Reference \\
\hline $\begin{array}{l}\text { Babesia spp./Hepatozoon } \\
\text { spp. }\end{array}$ & $\begin{array}{l}\text { Piroplasmid-F: CCAGCAGCCGCGGTA } \\
\text { ATTC } \\
\text { Piroplasmid-R: CTTTCGCAGTAGTTYGTC } \\
\text { TTTAACAAATCT }\end{array}$ & 185 rRNA & $350-400$ & $\begin{array}{l}95^{\circ} \mathrm{C} \text { for } 10 \text { min initial denaturation, followed by } 35 \\
\text { cycles of } 95^{\circ} \mathrm{C} \text { for } 30 \mathrm{~s}, 64^{\circ} \mathrm{C} \text { for } 20 \mathrm{~s}, 72^{\circ} \mathrm{C} \text { for } 20 \mathrm{~s} \text {, then } \\
72^{\circ} \mathrm{C} \text { for } 7 \text { min for the final elongation }\end{array}$ & [38] \\
\hline $\begin{array}{l}\text { Ehrlichia spp./Anaplasma } \\
\text { spp. }\end{array}$ & $\begin{array}{l}\text { EHR16SD: GGTACCYACAGAAGAAGTCC } \\
\text { EHR16SR:TAGCACTCATCGTTTACA GC }\end{array}$ & 165 rRNA & 345 & $\begin{array}{l}95^{\circ} \mathrm{C} \text { for } 10 \text { min initial denaturation, followed by } 35 \\
\text { cycles of } 95^{\circ} \mathrm{C} \text { for } 30 \mathrm{~s}, 60^{\circ} \mathrm{C} \text { for } 30 \mathrm{~s}, 72^{\circ} \mathrm{C} \text { for } 30 \mathrm{~s} \text {, then } \\
72^{\circ} \mathrm{C} \text { for } 10 \text { min for the final elongation }\end{array}$ & [39] \\
\hline Coxiella burnetii & $\begin{array}{l}\text { Trans-1: TATGTATCCACCGTAGCCAGT } \\
\text { Trans-2: CCCAACAACACCTCCTTATTC }\end{array}$ & IS1111a & 687 & $\begin{array}{l}95^{\circ} \mathrm{C} \text { for } 10 \text { min initial denaturation, followed by } 35 \\
\text { Cycles of } 95^{\circ} \mathrm{C} \text { for } 30 \mathrm{~s}, 64^{\circ} \mathrm{C} \text { for } 60 \mathrm{~s}, 72^{\circ} \mathrm{C} \text { for } 60 \mathrm{~s} \text {, then } \\
72^{\circ} \mathrm{C} \text { for } 7 \text { min for the final elongation }\end{array}$ & [40] \\
\hline Bartonella spp. & $\begin{array}{l}\text { ssrA-F: GCTATGGTAATAAATGGACAA } \\
\text { TGAAATAA } \\
\text { ssrA-R: GCTTCTGTTGCCAGGTG } \\
\text { Probe: FAM-ACCCCGCTTAAACCTGCG } \\
\text { ACG }\end{array}$ & $s s r A$ & 301 & $\begin{array}{l}95^{\circ} \mathrm{C} \text { for } 2 \text { min initial denaturation, followed by } 45 \text { cycles } \\
\text { of } 95^{\circ} \mathrm{C} \text { for } 15 \mathrm{~s}, 60^{\circ} \mathrm{C} \text { for } 60 \mathrm{~s}\end{array}$ & [41] \\
\hline Rickettsia spp. & $\begin{array}{l}\text { CS-78F: GCAAGTATCGGTGAGGATGTAAT } \\
\text { CS-323R: GCTTCCTTAAAATTCAATAAA } \\
\text { TCAGGAT }\end{array}$ & glt $A$ & 401 & $\begin{array}{l}95^{\circ} \mathrm{C} \text { for } 10 \text { min initial denaturation, followed by } 40 \\
\text { Cycles of } 95^{\circ} \mathrm{C} \text { for } 30 \mathrm{~s}, 58^{\circ} \mathrm{C} \text { for } 30 \mathrm{~s}, 72^{\circ} \mathrm{C} \text { for } 40 \mathrm{~s} \text {, then } \\
72^{\circ} \mathrm{C} \text { for } 7 \text { min for the final elongation }\end{array}$ & {$[42]$} \\
\hline $\begin{array}{l}\text { Spotted fever group } \\
\text { rickettsiae }\end{array}$ & $\begin{array}{l}\text { Rr190.70F: ATGGCGAATATTTCTCCAAAA } \\
\text { Rr190.701R: GTTCCGTTAATGGCAGCA } \\
\text { TCT }\end{array}$ & ompA & 632 & $\begin{array}{l}95^{\circ} \mathrm{C} \text { for } 10 \text { min initial denaturation, followed by } 35 \\
\text { cycles of } 94^{\circ} \mathrm{C} \text { for } 40 \mathrm{~s}, 58^{\circ} \mathrm{C} \text { for } 30 \mathrm{~s}, 72^{\circ} \mathrm{C} \text { for } 45 \mathrm{~s} \text {, then } \\
72^{\circ} \mathrm{C} \text { for } 10 \text { min for the final elongation }\end{array}$ & {$[43]$} \\
\hline
\end{tabular}

in the GenBank database using Basic Local Alignment Search Tool (http://blast.ncbi.nlm.nih.gov/Blast.cgi).

To assess the genetic variation of $R h$. sanguineus (s.l.) and Rickettsia spp., the mitochondrial $16 S$ rDNA sequences of Rh. sanguineus (s.l.) ticks generated previously [10] as well as the gltA and ompA gene sequences of Rickettsia spp. generated herein were subjected to phylogenetic analysis. Phylogenetic relationship was inferred by Maximum Likelihood (ML) method after selecting the best-fitting substitution model. Evolutionary analysis was conducted on 8000 bootstrap replications using the MEGA 7 software [44].

\section{Statistical analysis}

The percentage of detected pathogens was calculated and 95\% confidence intervals (95\% CI) (by the modified Wald method) were estimated by using Quantitative Parasitology 3.0 software [45]. Fisher's exact test was performed to analyze statistically significant differences in the detection of pathogens in fleas and ticks, and in the distribution of different Rickettsia spp. among different flea species using SPSS 16.0 software. Differences were considered significant at $P<0.05$.

\section{Results}

The occurrence of VBPs has been detected in ticks and fleas, with a higher number of fleas in which at least one pathogen was detected compared to ticks (Fisher's exact test, $P<0.001)$. Of the 392 ticks tested, 37 (9.4\%; 95\% CI: 6.9-12.8\%) scored positive for at least one pathogen with $H$. canis being the most prevalent (5.4\%; 95\% CI: 3.5-8.1\%), followed by E. canis (1.8\%; 95\% CI: 0.8-3.7\%), B. vogeli (1\%; 95\% CI: 0.3-2.7\%), Rickettsia spp. (1\%; 95\% CI: $0.3-2.7 \%$ ) and A. platys (0.8\%; 95\% CI: $0.2-2.3 \%)$. Co-infection of A. platys and B. vogeli was detected in one Rh. sanguineus (s.l.), whereas none of the ticks tested positive for $C$. burnetii (Table 2). Out of 248 fleas tested, 106 (42.7\%; 95\% CI: 36.7-49.0\%) were harboring at least one pathogen with $R$. felis being the most common (19.4\%; 95\% CI: 14.9-24.8\%), followed by Bartonella spp. (16.5\%; 95\% CI: 12.4-21.7\%), Rickettsia asembonensis (10.9\%; 95\% CI: 7.6-15.4\%) and "Candidatus Rickettsia senegalensis" (0.4\%; 95\% CI: <0.0001-2.5\%) (Table 3). Rickettsia felis was mostly detected in C. felis, whereas C. orientis mainly harbored $R$. asembonensis $(P<0.001)$.

Representative nucleotide sequences for each detected pathogen displayed 99.4-100\% identity with those available in GenBank database. In particular, $A$. platys nucleotide sequences $(n=3)$ revealed $99.6-100 \%$ identity with KU500914 (host: Canis lupus familiaris; origin: Malaysia), H. canis $(n=20) 99.7-100 \%$ identity with DQ519358 (host: C. lupus familiaris; origin: Thailand), E. canis $(n=7)$ and B. vogeli $(n=4) 100 \%$ identical to MN227484 (host: C. lupus familiaris; origin: Iraq) and KX082917 (host: C. lupus familiaris; origin: Angola), respectively. 
Table 2 Pathogens detected in ticks according to their species, developmental stage, sex and host in East and Southeast Asia

\begin{tabular}{|c|c|c|c|c|c|c|c|}
\hline & \multicolumn{2}{|l|}{ Anaplasmataceae } & \multicolumn{3}{|l|}{ Rickettsia spp. } & \multicolumn{2}{|c|}{ Apicomplexan protozoans } \\
\hline & Anaplasma platys & Ehrlichia canis & Rickettsia felis & $\begin{array}{l}\text { Rickettsia } \\
\text { asembonensis }\end{array}$ & Rickettsia sp. & Babesia vogeli & Hepatozoon canis \\
\hline China $(n=28)$ & & & & & & & 1 \\
\hline \multicolumn{8}{|l|}{ C; Haemaphysalis longicornis (1L) } \\
\hline \multicolumn{8}{|l|}{ D; Haemaphysalis campanulata (1L) } \\
\hline \multicolumn{8}{|l|}{$\begin{array}{l}\text { D; Haemaphysalis longicornis (3L, } \\
1 \mathrm{~N}, 1 \mathrm{~F}, 1 \mathrm{M})\end{array}$} \\
\hline $\begin{array}{l}\text { D; Rhipicephalus sanguineus (s.l.) (3L, } \\
\quad 7 \mathrm{~N}, 5 \mathrm{~F}, 5 \mathrm{M})\end{array}$ & & & & & & & $1 \mathrm{~F}$ \\
\hline Indonesia $(n=79)$ & & 2 & & 1 & & & \\
\hline $\begin{array}{l}\text { C; Rhipicephalus sanguineus (s.l.) (2N, } \\
6 \mathrm{~F}, 2 \mathrm{M})\end{array}$ & & $1 F$ & & & & & \\
\hline $\begin{array}{l}\text { D; Rhipicephalus sanguineus (s.l.) (2L, } \\
\text { 10N, 26F, 30M) }\end{array}$ & & $1 F$ & & $1 \mathrm{~F}$ & & & \\
\hline \multicolumn{8}{|l|}{ D; Haemaphysalis wellingtoni (1N) } \\
\hline Malaysia $(n=3)$ & 2 & & & & & 1 & \\
\hline $\begin{array}{l}\text { D; Rhipicephalus sanguineus (s.l.) } \\
(1 \mathrm{~F}, 2 \mathrm{M})\end{array}$ & $1 F, 1 M$ & & & & & $1 \mathrm{M}$ & \\
\hline The Philippines $(n=90)$ & & 2 & 1 & & & & 12 \\
\hline $\begin{array}{l}\text { C; Rhipicephalus sanguineus (s.l.) (6N, } \\
\text { 8F, 13M) }\end{array}$ & & $1 \mathrm{~N}, 1 \mathrm{~F}$ & & & & & $1 \mathrm{~N}, 1 \mathrm{M}$ \\
\hline $\begin{array}{l}\text { D; Rhipicephalus sanguineus (s.l.) (1L, } \\
6 \mathrm{~N}, 23 \mathrm{~F}, 33 \mathrm{M})\end{array}$ & & & $1 \mathrm{M}$ & & & & $1 \mathrm{~N}, 2 \mathrm{~F}, 7 \mathrm{M}$ \\
\hline \multicolumn{8}{|l|}{ Singapore $(n=4)$} \\
\hline \multicolumn{8}{|l|}{$\begin{array}{l}\text { C; Rhipicephalus sanguineus (s.l.) }(1 \mathrm{~N}, \\
1 \mathrm{~F}, 2 \mathrm{M})\end{array}$} \\
\hline Taiwan $(n=25)$ & 1 & & & & 2 & & 1 \\
\hline \multicolumn{8}{|l|}{$C_{i}$ Ixodes sp. $(1 F)^{a}$} \\
\hline $\begin{array}{l}\text { D; Rhipicephalus haemaphysaloides } \\
\quad(1 \mathrm{~F}, 2 \mathrm{M})\end{array}$ & & & & & $1 \mathrm{~F}, 1 \mathrm{M}$ & & \\
\hline $\begin{array}{l}\text { D; Rhipicephalus sanguineus (s.l.) (2N, } \\
\text { 9F, 10M) }\end{array}$ & $1 \mathrm{M}$ & & & & & & $1 \mathrm{~F}$ \\
\hline Thailand $(n=46)$ & & 3 & & & & & 1 \\
\hline \multicolumn{8}{|l|}{ D; Haemaphysalis hystricis (1F) } \\
\hline \multicolumn{8}{|l|}{ D; Haemaphysalis wellingtoni (1L) } \\
\hline $\begin{array}{l}\text { D; Rhipicephalus sanguineus (s.l.) (2L, } \\
3 \mathrm{~N}, 20 \mathrm{~F}, 9 \mathrm{M})\end{array}$ & & $1 F, 2 M$ & & & & & $1 \mathrm{~F}$ \\
\hline Vietnam $(n=117)$ & & & & & & 3 & 6 \\
\hline $\begin{array}{l}\text { D; Rhipicephalus sanguineus (s.l.) } \\
(18 \mathrm{~N}, 48 \mathrm{~F}, 51 \mathrm{M})\end{array}$ & & & & & & $2 \mathrm{~F}, 1 \mathrm{M}$ & $5 F, 1 M$ \\
\hline Total & 3 & 7 & 1 & 1 & 2 & 4 & 21 \\
\hline
\end{tabular}

Abbreviations: $C$, cat; $D$, dog; $L$, larva; $N$, nymph; $M$, adult male; $F$, adult female

a This female tick was reported as "Ixodes sp." in [10]. Following reassessment of photomicrography images of this tick by one of the co-authors (F.D.-T.) the following morphological features were observed: auriculae and cornua present; porose area small, not contiguous, hypostome with a $2 / 2$ dental formula on almost the entire hypostome; coxa I with slight internal spur, coxae III and IV each with external spur; syncoxae present on coxae I and II; trochanters lacking spurs. As such, this female shares several morphological features with /xodes ovatus [46], but genetic data from a partial 16S rDNA sequence (percent identity: $90.7 \%$ with U95900) suggest that this may belong to a distinct species

For Rickettsia spp. detection in ticks, the gltA sequence identified in one tick showed $99.7 \%$ identity with $R$. asembonensis (GenBank: KY445723; host: C. felis; origin: Brazil) and another was identical to R. felis (100\% nucleotide identity with MG845522 (host: C. felis; origin: Chile) and $99.4 \%$ nucleotide identity with $R$. felis strain
URRWXCal2; GenBank: CP000053 (source: cultivation; origin: USA)). The ompA gene amplification was successful for two samples which showed $100 \%$ nucleotide identity with unidentified Rickettsia sp. (GenBank: EF219467; host: $R$. haemaphysaloides; origin: Taiwan), which was 
Table 3 Pathogens detected in fleas according to their species, developmental stage, sex and host in East and Southeast Asia

\begin{tabular}{|c|c|c|c|c|}
\hline & \multicolumn{3}{|c|}{ Rickettsia spp. } & \multirow[t]{2}{*}{ Bartonella spp. } \\
\hline & R. felis & R. asembonensis & "Ca. R. senegalensis" & \\
\hline China $(n=17)$ & 1 & & & 2 \\
\hline C; Ctenocephalides felis (8F, 2M) & $1 \mathrm{~F}$ & & & $2 \mathrm{~F}$ \\
\hline \multicolumn{5}{|l|}{ D; Ctenocephalides felis (7F) } \\
\hline Indonesia $(n=48)$ & 12 & 9 & & 21 \\
\hline C; Ctenocephalides felis $(4 \mathrm{~F}, 24 \mathrm{M})$ & $7 F, 2 M$ & & & $18 \mathrm{~F}$ \\
\hline C; Xenopsylla cheopis (1M) & & & & $1 \mathrm{M}$ \\
\hline D; Ctenocephalides felis (6F, 1M) & $2 \mathrm{~F}$ & & & $2 \mathrm{~F}$ \\
\hline D; Ctenocephalides orientis (9F, 3M) & $1 \mathrm{M}$ & $7 F, 2 M$ & & \\
\hline \multicolumn{5}{|l|}{ Malaysia $(n=7)$} \\
\hline \multicolumn{5}{|l|}{ C; Ctenocephalides felis (4F, 1M) } \\
\hline \multicolumn{5}{|l|}{ D; Ctenocephalides felis (2F) } \\
\hline The Philippines $(n=90)$ & 20 & 9 & & 4 \\
\hline C; Ctenocephalides felis (24F, 9M) & $4 \mathrm{~F}, 3 \mathrm{M}$ & & & $3 \mathrm{~F}, 1 \mathrm{M}$ \\
\hline D; Ctenocephalides felis (34F, 13M) & $12 \mathrm{~F}, 1 \mathrm{M}$ & $1 \mathrm{~F}$ & & \\
\hline D; Ctenocephalides orientis (9F, 1M) & & $8 \mathrm{~F}$ & & \\
\hline Singapore $(n=2)$ & & & & 2 \\
\hline C; Ctenocephalides felis (1M) & & & & $1 \mathrm{M}$ \\
\hline C; Ctenocephalides orientis (1F) & & & & $1 \mathrm{~F}$ \\
\hline Taiwan $(n=24)$ & 8 & & & 4 \\
\hline C; Ctenocephalides felis (10F, 4M) & $3 \mathrm{~F}, 2 \mathrm{M}$ & & & $3 \mathrm{~F}, 1 \mathrm{M}$ \\
\hline D; Ctenocephalides felis (6F, 3M) & $3 F$ & & & \\
\hline \multicolumn{5}{|l|}{ D; Ctenocephalides orientis (1F) } \\
\hline Thailand $(n=21)$ & 1 & 4 & 1 & 5 \\
\hline C; Ctenocephalides felis (4F, 1M) & & & & $2 \mathrm{~F}$ \\
\hline D; Ctenocephalides felis (7F, 4M) & $1 F$ & & & $1 F$ \\
\hline $\mathrm{D} ;$ Ctenocephalides orientis $(2 \mathrm{~F}, 3 \mathrm{M})$ & & $2 \mathrm{~F}, 2 \mathrm{M}$ & $1 \mathrm{M}$ & $1 F_{1} 1 \mathrm{M}$ \\
\hline Vietnam $(n=39)$ & 6 & 5 & & 3 \\
\hline C; Ctenocephalides felis $(14 \mathrm{~F}, 5 \mathrm{M})$ & $3 \mathrm{~F}, 1 \mathrm{M}$ & & & $3 F$ \\
\hline D; Ctenocephalides felis (8F, 3M) & $2 \mathrm{~F}$ & & & \\
\hline D; Ctenocephalides orientis (7F, 2M) & & $4 \mathrm{~F}, 1 \mathrm{M}$ & & \\
\hline Total & 48 & 27 & 1 & 41 \\
\hline
\end{tabular}

Abbreviations: $\mathrm{C}$, cat; D, dog; F, female; M, male

related (98.3\%) to Rickettsia rhipicephali (GenBank: U43803; host: C. felis; origin: USA).

For Rickettsia spp. detection in fleas, amplification of a portion of the gltA gene was positive from 76 fleas. The partial sequence of the $o m p A$ gene was successfully obtained from 17 of the 76 glt $A$-positive $C$. felis fleas. All of those $o m p A$ gene sequences were $100 \%$ identical to R. felis strain URRWXCal2 (GenBank: CP000053; source: cultivation; origin: USA). Sequence analysis of the gltA genes fragment from the other 59 Rickettsia positive $C$. felis fleas revealed that the 31 sequences obtained had $99.4 \%$ nucleotide identity with $R$. felis strain URRWXCal2 (GenBank: CP000053; source: cultivation; origin: USA), 27 sequences $99.7 \%$ with $R$. asembonensis (GenBank: KY445723; host: C. felis; origin: Brazil) and one $100 \%$ with "Ca. R. senegalensis" (GenBank: MK548197; host: C. felis; origin: Colombia).

The phylogenetic tree based on the partial ompA gene sequences showed that all $R$. felis isolated from fleas were assembled together in one cluster, whereas Rickettsia sp. isolated from ticks clustered with $R$. rhipicephali and Rickettsia massiliae (Fig 1). In the gltA tree, phylogenetical analysis revealed that $R$. felis, $R$. asembonensis and "Ca. R. senegalensis" herein detected were formed together in a well-supported sister cluster include other R. felis-like organisms (RFLOs), close to the cluster of Rickettsia australis and Rickettsia akari (Fig. 2). 


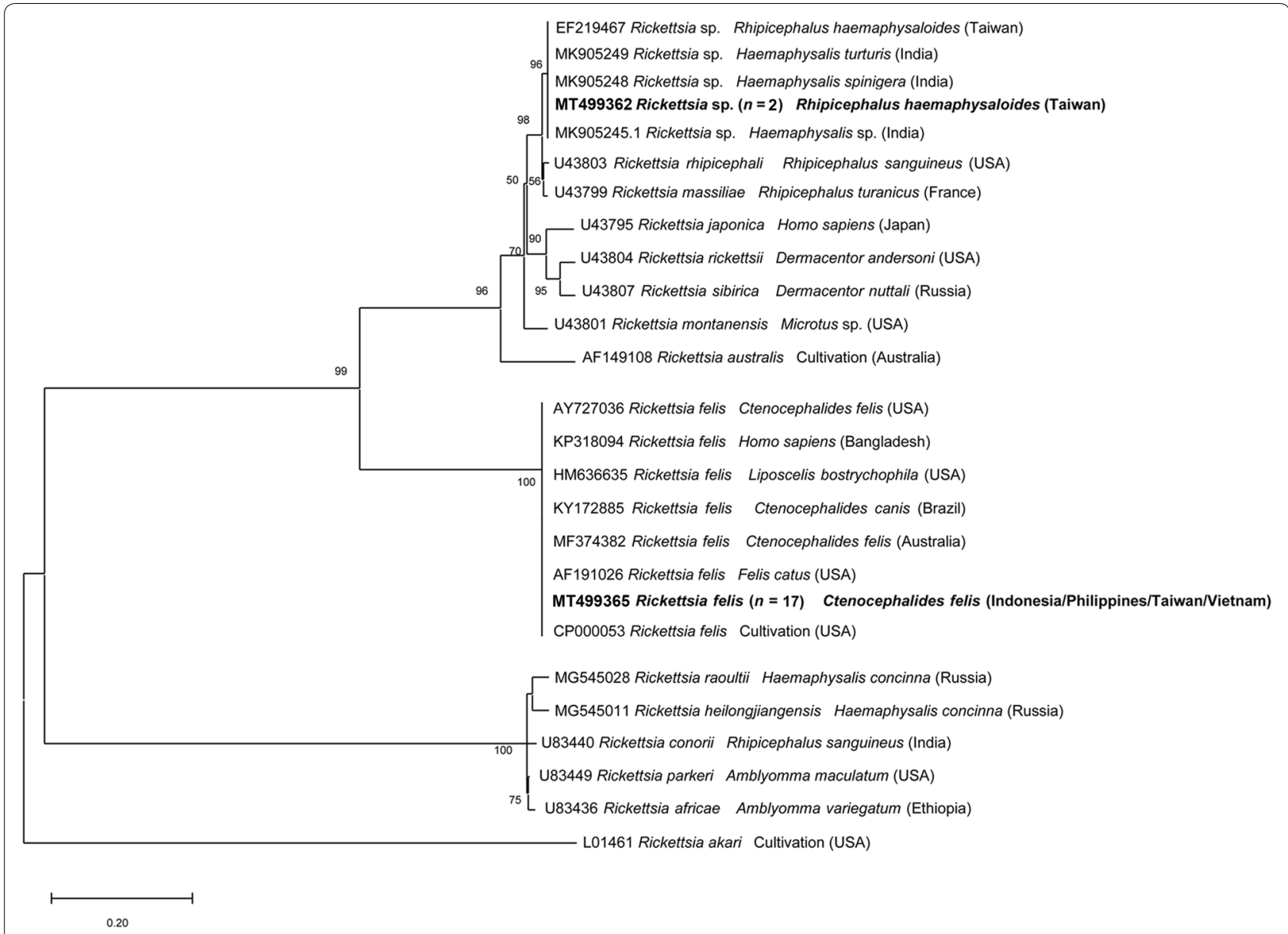

Fig. 1 Phylogenetic relationships of Rickettsia spp. isolated in this study (in bold) to other Rickettsia spp. based on partial sequences of the ompA gene. The analyses were performed using a Maximum Likelihood method with Tamura 3-parameter model. A discrete Gamma distribution was used to model evolutionary rate differences among sites. GenBank accession number, isolation source and country of origin are presented for each sequence

The ML tree of 35 representative mitochondrial $16 S$ rDNA sequences of Rh. sanguineus (s.l.) gene showed that 34 sequences were identical to each other and identified as belong to the tropical lineage of Rh. sanguineus (s.l.) (100\% identity with GU553075; origin: Brazil). One sequence from a tick collected from a dog in Beijing (northeast China) clustered with Rh. sanguineus (sensu stricto) (100\% identity with GU553078; origin: Argentina) (Fig. 3).

Representative sequences of pathogens detected in this study were deposited in the GenBank database under the accession numbers MT499354-MT499356 (H. canis), MT499357 (B. vogeli), MT499358 and MT499359 (A. platys), MT499360 and MT499361 (E. canis), MT499362 (Rickettsia sp.), MT499363-MT499367 (R. felis), MT499368-MT499370 (R. asembonensis) and MT499371 (“Ca. R. senegalensis").

\section{Discussion}

The results of this study reveal the presence of several pathogens in ticks (e.g. A. platys, B. vogeli, E. canis, $H$. canis and Rickettsia spp.) and fleas (e.g. Rickettsia spp. and Bartonella spp.) collected from dogs and cats in EA and SEA. The relatively low occurrence of pathogens herein detected in ticks is consistent with previous surveys conducted in ticks infesting owned dogs in Asia [13, 26, 47-49]. Conversely, the occurrence of VBPs is higher in ticks collected from stray animals [24]. Although $B$. gibsoni was identified in dogs from China (2.3\%; [10]), none of the tested ticks from these dogs was found positive for this parasite. The absence of $B$. gibsoni in tick populations is probably due to the low number of $H$. longicornis and $H$. hystricis, which are recognized as vectors of this pathogen [50,51]. The infection of E. canis $(14.8 \%$ by serology) and $H$. canis (1.6\% by cPCR) in host populations [10], along with the detection of these pathogens 


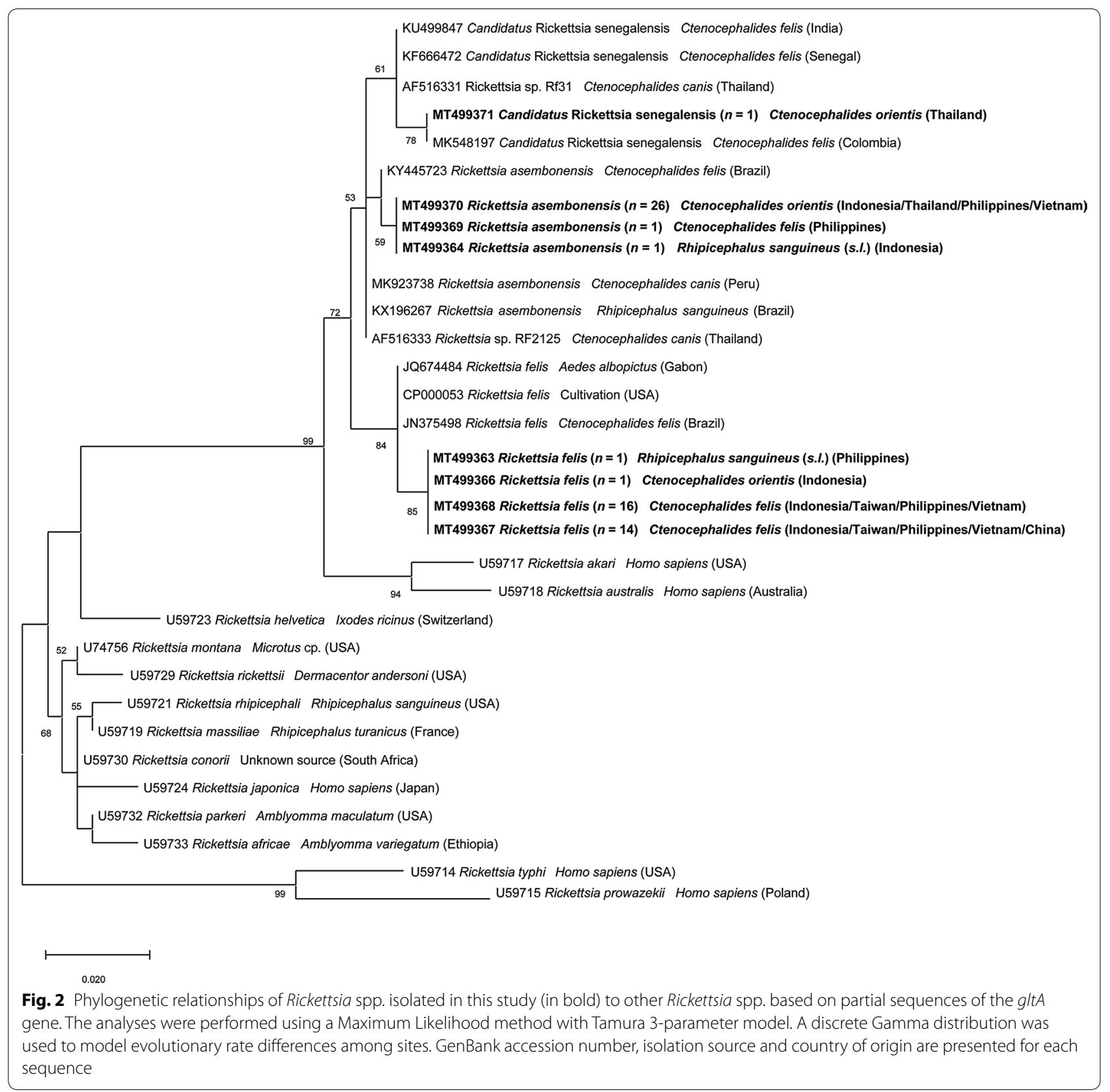

in Rh. sanguineus (s.l.) in the sampling areas support the vector role of this tick species in the transmission of these VBPs in this region $[11,14]$. The finding of $A$. platys in dogs (7.1\% by serology; [10]) and in Rh. sanguineus (s.l.) further suggests its vector competence for this pathogen. Additionally, the detection of $R$. felis and $R$. asembonensis in Rh. sanguineus (s.l.) is similar to previous results in Chile [52], Brazil [53] and Malaysia [54], consequently giving more concern about the role of $R h$. sanguineus (s.l.) in the transmission of Rickettsia spp. other than $R$. conorii, $R$. massiliae and $R$. rickettsii $[4,55]$. Rickettsia sp. sequences herein obtained from $R h$. haemaphysaloides are identical to one previously generated from the same tick species in Taiwan (named Rickettsia sp. TwKM01) [56]. This genotype and its closest related species $R$. rhipicephali remain of unknown pathogenicity to mammals [56, 57]. Additionally, the vector role of Rh. haemaphysaloides needs further investigations since it was found harboring multiple pathogens such as $R$. rhipicephali, $A$. platys, E. canis, B. gibsoni $[13,58]$.

Of the detected VBPs, $R$. felis stood out as the most important due to its wide distribution, association with 


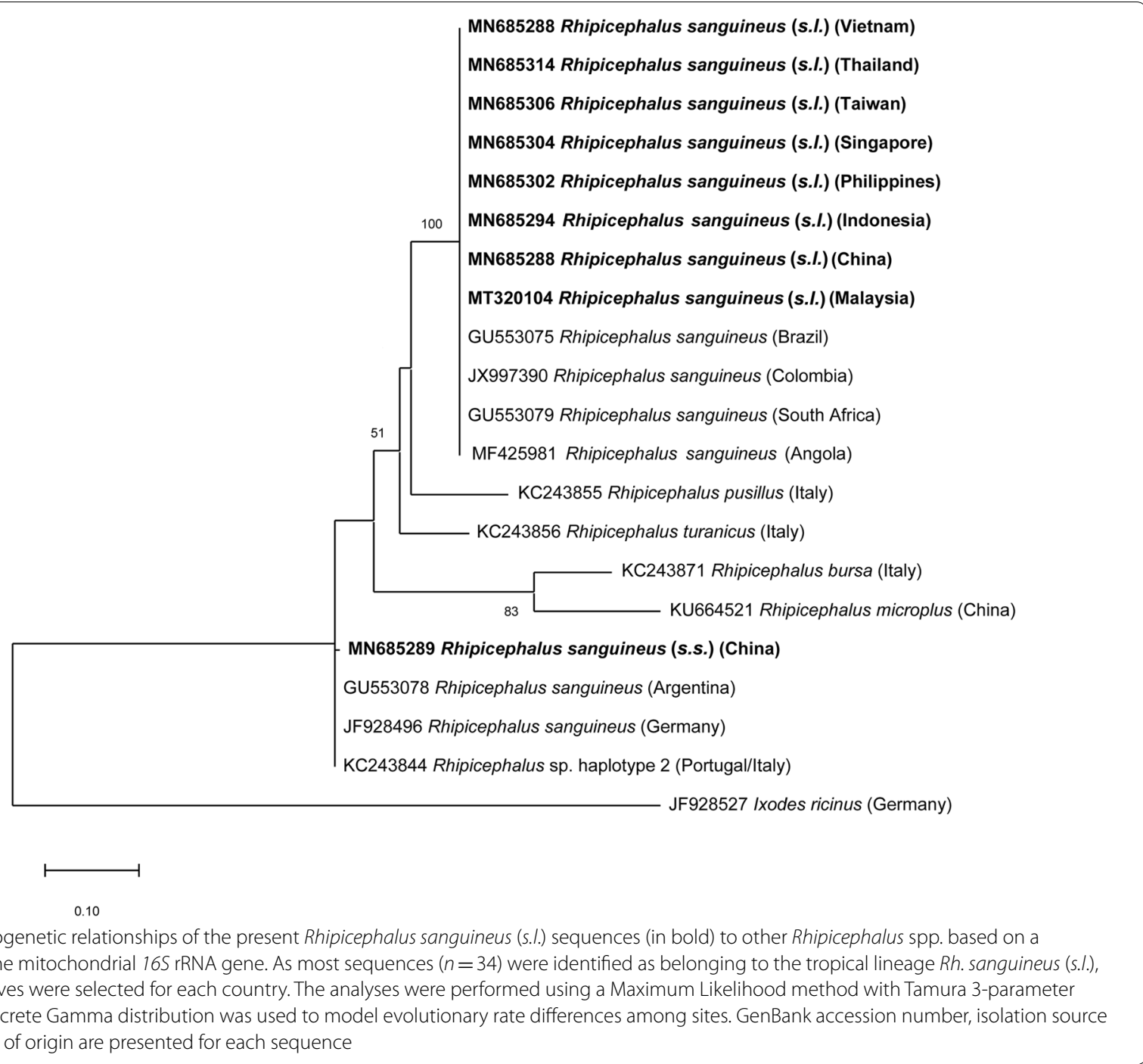

various arthropods, and importance as an emerging zoonotic pathogen [59]. In Asia, the first human case of flea-borne spotted fever attributed to $R$. felis was detected in the Thai-Myanmar border [60], since then several cases of human infection have been documented in Taiwan [61], Thailand [62], Laos [63], Vietnam [64] and Indonesia [65]. Although $R$. felis was detected in many arthropods, including non-hematophagous insect (i.e. the book louse Liposcelis bostrychophila) [66], the distribution of this rickettsia is highly affiliated with the distribution of C. felis [59]. Ctenocephalides felis is the most well-recognized vector of this rickettsia, which is transmitted transovarially and transstadially in the fleas [67], with dogs as proven mammalian reservoir hosts [68]. The high occurrence of $R$. felis in $C$. felis along with the high relative frequency of this flea species in host populations (65.1\% in dogs and $98.7 \%$ in cats) [10] emphasizes the risk of $R$. felis infection in animals and humans.
The detection of $R$. asembonensis only from fleas collected on dogs (mainly C. orientis but in one case in C. felis) may suggest that dogs could act as amplifying hosts of this rickettsia, as they do for R. felis [68]. Rickettsia asembonensis is the most well-characterized genotype of RFLOs [69]. This rickettsia was initially described in fleas from dogs and cats in Kenya [70] and was then reported in various arthropods worldwide [69]. In Asia, R. asembonensis was also found in C. orientis from dogs [54] and in macaques from Malaysia [71]. Additionally, Rickettsia sp. RF2125, a genotype highly related to $R$. asembonensis, was reported with high incidence in $C$. orientis from India and Thailand $[72,73]$, and was also found in a febrile patient from Malaysia [74]. Moreover, $R$. felis, $R$. asembonensis and "Ca. R. senegalensis" clustered in the SFG rickettsiae clade (Fig. 3), and while $R$. felis is a recognized 
pathogen [67], the pathogenicity of other RFLOs is currently unknown.

Besides acting as vectors of Rickettsia spp., fleas have been well-recognized as vectors of Bartonella spp. [6, 75]. The occurrence of Bartonella-positive fleas in our study was slightly lower than previous investigations in Laos [30], Malaysia [35] and Thailand [76]. Nevertheless, the occurrence of the two common Bartonella spp. (i.e. B. henselae and B. clarridgeiae) in dogs and cats from EA and SEA is relatively high; up to $60 \%[18,31,76,77]$. Additionally, $B$. henselae infection in humans is usually associated to previous exposure to cats or cat fleas [78], emphasizing the role of cat fleas in Bartonella spp. transmission between animals and humans.

In the present study, all tested tick specimens were negative for $C$. burnetii although this pathogen was detected in Rh. sanguineus (s.l.) from dogs in Malaysia [79], in dogs in Taiwan [80] and in humans from Thailand [81]. Additionally, Coxiella-like endosymbionts were strongly associated with $R h$. sanguineus (s.l.) tropical lineage [82], although the role of these endosymbionts in the biology and vectoral capacity of this tick lineage needs further investigation.

Finally, the genetic lineage of Rh. sanguineus (s.l.) from EA and SEA was investigated based on the $16 S$ rDNA sequences. The finding of Rh. sanguineus (s.s.) in Beijing, a cold area, along with the existence of the tropical lineage in warmer localities, agreed with previous studies, which indicated that the tropical lineage is present in areas with annual mean temperature $>20^{\circ} \mathrm{C}$, whereas the temperate lineage occurs in areas with annual mean temperature $<20^{\circ} \mathrm{C}$ [83]. This information is also relevant from a pathogen transmission perspective, considering that different $R h$. sanguineus (s.l.) lineages may present variable vector competence and/or capacity for different pathogens; for instance, $E$. canis is primarily vectored by Rh. sanguineus (s.l.) tropical lineage [84].

\section{Conclusions}

Data herein reported updates the list of pathogens occurring in ticks and fleas from companion dogs and cats in EA and SEA. By sharing the common environment with humans, these parasitic arthropods could be responsible for the transmission of pathogens to humans (i.e. R. felis). Strategies to prevent tick and flea infestations in these animals are fundamental to decrease the risk of transmission of VBPs to animals and humans.

\section{Acknowledgements}

The authors would like to thank and acknowledge all collaborators from collected sites and animal owners for their participation in the study. In particular Do Yew Tan, Na Lu, Yin Zhijuan, Jiangwei Wang, Xin Liu, Xinghui Chen, Dang Anh Thy, Junyan Dong, Isabelle Von Richthofen, Evonne Lim, Clair Chen, Mickael Banawa, and Marielle Servonnet.

\section{Authors' contributions}

$\mathrm{DO}$ and $\mathrm{VC}$ conceived the study. FF, WN, UKH, WV, KBYT, YLT, PT, STi, STa, TQL, $\mathrm{KLB}, \mathrm{TD}, \mathrm{MW}$ and PAMAR performed field works. VLN and GG performed the molecular identification of pathogens. VLN analyzed data. VLN and DO wrote the first draft of the manuscript. VC, FDT, LH and FB reviewed the manuscript. All authors read and approved the final manuscript.

\section{Funding}

This study was supported by Boehringer Ingelheim Animal Health, Global Technical Services, Companion Animals Parasitology (France) with a grant at the University of Bari, Italy (grant number: D17CTMerial2 - Prog. C/T "A Multicenter Study of Dogs and Cats Parasites in East and Southeast Asia").

\section{Availability of data and materials}

All data generated or analyzed during this study are included in this published article. Representative newly generated sequences were submitted in the GenBank database under the accession numbers MT499354-MT499356 (H. canis), MT499357 (B. vogeli), MT499358 and MT499359 (A. platys), MT499360 and MT499361 (E. canis), MT499362 (Rickettsia sp.), MT499363-MT499367 (R. felis), MT499368-MT499370 (R. asembonensis) and MT499371 ("Ca. R. senegalensis").

\section{Ethics approval and consent to participate}

The protocol of this study was approved by the Ethical Committee of the Department of Veterinary Medicine of the University of Bari (Prot. no. 13/17). All animals' owners have read, approved and signed an owner informed consent which contained information on study procedures and aims of this study.

\section{Consent for publication}

Not applicable.

\section{Competing interests}

The authors declare that they have no competing interests.

\section{Author details}

${ }^{1}$ Dipartimento di Medicina Veterinaria, Università degli Studi di Bari, Bari, Italy. ${ }^{2}$ Faculty of Veterinary and Agricultural Sciences, University of Melbourne, Melbourne, Australia. ${ }^{3}$ School of Animal Science and Technology, Guangxi University, Nanning, China. ${ }^{4}$ Faculty of Veterinary Medicine, Gadjah Mada University, Yogyakata, Indonesia. ${ }^{5}$ Faculty of Veterinary Medicine, IPB University, Bogor, Indonesia. ${ }^{6}$ College of Veterinary Science \& Medicine, Central Luzon State University, Nueva Ecija, Philippines. ${ }^{7}$ Animal \& Avian Veterinary Clinic, Singapore, Singapore. ${ }^{8}$ Department of Veterinary Medicine, National Pingtung University of Science and Technology, Pingtung, Taiwan. ${ }^{9}$ Faculty of Veterinary Science, Chualalongkorn University, Bangkok, Thailand. ${ }^{10}$ Faculty of Veterinary Medicine, Chiang Mai University, Chiang Mai, Thailand. ${ }^{11}$ Faculty of Animal Science \& Veterinary Medicine, Nong Lam University, Ho Chi Minh city, Vietnam.

${ }^{12}$ Faculty of Veterinary Medicine, Vietnam National University of Agriculture, Hanoi, Vietnam. ${ }^{13}$ Biodiversity Conservation and Tropical Disease Research Institute, Hanoi, Vietnam. ${ }^{14}$ Faculty of Veterinary Medicine, Universiti Putra Malaysia, Serdang, Malaysia. ${ }^{15}$ Department of Immunology, Aggeu Magalhães Institute, Recife, Brazil. ${ }^{16}$ Boehringer Ingelheim Animal Health, Lyon, France.

${ }^{17}$ Faculty of Veterinary Sciences, Bu-Ali Sina University, Hamedan, Iran.

Received: 12 June 2020 Accepted: 3 August 2020

Published online: 15 August 2020

References

1. Otranto D, Dantas-Torres F, Breitschwerdt EB. Managing canine vector-borne diseases of zoonotic concern: part one. Trends Parasitol. 2009;25:157-63.

2. Otranto D, Dantas-Torres F. Canine and feline vector-borne diseases in Italy: current situation and perspectives. Parasit Vectors. 2010;3:2.

3. Dantas-Torres F, Chomel BB, Otranto D. Ticks and tick-borne diseases: a one health perspective. Trends Parasitol. 2012;28:437-46.

4. Dantas-Torres F, Otranto D. Further thoughts on the taxonomy and vector role of Rhipicephalus sanguineus group ticks. Vet Parasitol. 2015;208:9-13. 
5. Chomel BB, Kasten RW, Floyd-Hawkins K, Chi B, Yamamoto K, RobertsWilson J, et al. Experimental transmission of Bartonella henselae by the cat flea. J Clin Microbiol. 1996;34:1952-6.

6. Greco G, Brianti E, Buonavoglia C, Carelli G, Pollmeier M, Schunack B, et al. Effectiveness of a $10 \%$ imidacloprid/45\% flumethrin polymer matrix collar in reducing the risk of Bartonella spp. infection in privately owned cats. Parasit Vectors. 2019:12:69.

7. Hirunkanokpun S, Thepparit C, Foil LD, Macaluso KR. Horizontal transmission of Rickettsia felis between cat fleas, Ctenocephalides felis. Mol Ecol. 2011;20:4577-86.

8. International Money Fund: Real GDP growth. https://www.imf.org/exter nal/datamapper/NGDP_RPCH@WEO/OEMDC/ADVEC/WEOWORLD. Accessed 2 Jun 2020

9. The economist: Pet-ownership is booming across the world. https:// www.economist.com/international/2019/06/22/pet-ownership-is-boomi ng-across-the-world. Accessed 2 Jun 2020

10. Colella V, Nguyen VL, Tan DY, Lu N, Fang F, Zhijuan Y, et al. Zoonotic vectorborne pathogens and ectoparasites of dogs and cats in Eastern and Southeast Asia. Emerg Infect Dis. 2020;26:1221-33.

11. Irwin PJ, Jefferies R. Arthropod-transmitted diseases of companion animals in Southeast Asia. Trends Parasitol. 2004;20:27-34.

12. Iwakami S, Ichikawa Y, Inokuma H. A nationwide survey of ixodid tick species recovered from domestic dogs and cats in Japan in 2011. Ticks Tick Borne Dis. 2014;6:771-9.

13. Zhang J, Liu Q, Wang D, Li W, Beugnet F, Zhou J. Epidemiological survey of ticks and tick-borne pathogens in pet dogs in south-eastern China. Parasite. 2017:24:35

14. Petney TN, Saijuntha W, Boulanger N, Chitimia-Dobler L, Pfeffer M, Eamudomkarn C, et al. Ticks (Argasidae, Ixodidae) and tick-borne diseases of continental Southeast Asia. Zootaxa. 2019;4558:1-89.

15. Simking P, Wongnakphet S, Stich RW, Jittapalapong S. Detection of Babesia vogeli in stray cats of metropolitan Bangkok, Thailand. Vet Parasitol. 2010;173:70-5.

16. Zhang XL, Li XW, Li WJ, Huang HL, Huang SJ, Shao JW. Molecular evidence of Babesia in pet cats in mainland China. BMC Vet Res. 2019;15:476.

17. Xu D, Zhang J, Shi Z, Song C, Zheng X, Zhang Y, et al. Molecular detection of vector-borne agents in dogs from ten provinces of China. Parasit Vectors. 2015;8:501.

18. Inpankaew T, Hii SF, Chimnoi W, Traub RJ. Canine vector-borne pathogens in semi-domesticated dogs residing in northern Cambodia. Parasit Vectors. 2016;9:253.

19. Ybañez AP, Ybañez RHD, Talle MFG, Liu M, Moumouni PFA, Xuan X. First report on Babesia vogeli infection in dogs in the Philippines. Parasitol Int. 2017;66:813-5.

20. Prakash BK, Low VL, Vinnie-Siow WY, Tan TK, Lim YA, Morvarid AR, et al. Detection of Babesia spp. in dogs and their ticks from Peninsular Malaysia: emphasis on Babesia gibsoni and Babesia vogeli infections in Rhipicephalus sanguineus sensu lato (Acari: Ixodidae). J Med Entomol. 2018:55:1337-40

21. Lee $\mathrm{C}-\mathrm{C}$, Hsieh $\mathrm{Y}-\mathrm{C}$, Huang $\mathrm{C}-\mathrm{C}$, Tsang $\mathrm{C}-\mathrm{L}$, Chung $\mathrm{Y}-\mathrm{T}$. Sequence and phylogenetic analysis of the thrombospondin-related adhesive protein (TRAP) gene of Babesia gibsoni isolates from dogs in Taiwan. JVet Med Sci. 2010;72:1329-35.

22. Mokhtar AS, Lim SF, Tay ST. Molecular detection of Anaplasma platys and Babesia gibsoni in dogs in Malaysia. Trop Biomed. 2013;30:345-8.

23. Prakash BK, Low VL, Tan TK, Vinnie-Siow WY, Lim YA-L, Morvarid AR, et al. Detection of Hepatozoon canis in the brown dog tick and domestic dogs in Peninsular Malaysia. J Med Entomol. 2018;55:1346-8.

24. Jittapalapong S, Rungphisutthipongse O, Maruyama S, Schaefer JJ, Stich RW. Detection of Hepatozoon canis in stray dogs and cats in Bangkok, Thailand. Ann N Y Acad Sci. 2006;1081:479-88.

25. Huang C, Tsang C. Molecular characterization on 185 rRNA gene of Hepatozoon canis from suspected clinical infections in Taiwan dog cases. J Agri Fore. 2011;60:159-69.

26. Galay RL, Manalo AAL, Dolores SLD, Aguilar IPM, Sandalo KAC, Cruz KB, et al. Molecular detection of tick-borne pathogens in canine population and Rhipicephalus sanguineus (sensu lato) ticks from southern Metro Manila and Laguna, Philippines. Parasit Vectors. 2018;11:643.

27. Salakij C, Lertwatcharasarakul P, Salakij J, Nunklang K, Rattanakunuprakarn J. Molecular characterization of Anaplasma platys in a domestic cat from Thailand. Comp Clin Pathol. 2012;21:345-8.
28. Zhang J, Lu G, Kelly P, Zhang Z, Wei L, Yu D, et al. First report of Rickettsia felis in China. BMC Infect Dis. 2014;14:682.

29. Tsai KH, Huang CG, Fang CT, Shu PY, Huang JH, Wu WJ. Prevalence of Rickettsia felis and the first identification of Bartonella henselae Fizz/ CAL-1 in cat fleas (Siphonaptera: Pulicidae) from Taiwan. J Med Entomol. 2011;48:445-52.

30. Kernif T, Socolovschi C, Wells K, Lakim MB, Inthalad S, Slesak G, et al. Bartonella and Rickettsia in arthropods from the Lao PDR and from Borneo, Malaysia. Comp Immunol Microbiol Infect Dis. 2012;35:51-7.

31. Chomel BB, Carlos ET, Kasten RW, Yamamoto K, Chang CC, Carlos RS, et al. Bartonella henselae and Bartonella clarridgeiae infection in domestic cats from the Philippines. Am JTrop Med Hyg. 1999;60:593-7.

32. Marston EL, Finkel B, Regnery RL, Winoto IL, Graham RR, Wignal S, et al. Prevalence of Bartonella henselae and Bartonella clarridgeiae in an urban Indonesian cat population. Clin Diagn Lab Immunol. 1999;6:41-4.

33. Nasirudeen AM, Thong ML. Prevalence of Bartonella henselae immunoglobulin $\mathrm{G}$ antibodies in Singaporean cats. Pediatr Infect Dis J. 1999;18:276-8.

34. Maruyama S, Sakai T, Morita Y, Tanaka S, Kabeya H, Boonmar S, et al. Prevalence of Bartonella species and 16S rRNA gene types of Bartonella henselae from domestic cats in Thailand. Am J Trop Med Hyg. 2001;65:783-7.

35. Mokhtar AS, Tay ST. Molecular detection of Rickettsia felis, Bartonella henselae, and B. clarridgeiae in fleas from domestic dogs and cats in Malaysia. Am J Trop Med Hyg. 2011;85:931-3.

36. Yuan C, Zhu C, Wu Y, Pan X, Hua X. Bacteriological and molecular identification of Bartonella species in cats from different regions of China. PLOS Negl Trop Dis. 2011;5:e1301.

37. Latrofa MS, Angelou A, Giannelli A, Annoscia G, Ravagnan S, Dantas-Torres $F$, et al. Ticks and associated pathogens in dogs from Greece. Parasit Vectors. 2017;10:301.

38. Tabar MD, Altet L, Francino O, Sánchez A, Ferrer L, Roura X. Vector-borne infections in cats: molecular study in Barcelona area (Spain). Vet Parasitol. 2008;151:332-6.

39. Martin AR, Brown GK, Dunstan RH, Roberts TK. Anaplasma platys: an improved PCR for its detection in dogs. Exp Parasitol. 2005;109:176-80.

40. Berri M, Rekiki A, Boumedine KS, Rodolakis A. Simultaneous differential detection of Chlamydophila abortus, Chlamydophila pecorum and Coxiella burnetii from aborted ruminant's clinical samples using multiplex PCR. BMC Microbiol. 2009;9:130.

41. Diaz MH, Bai Y, Malania L, Winchell JM, Kosoy MY. Development of a novel genus-specific real-time PCR assay for detection and differentiation of Bartonella species and genotypes. J Clin Microbiol. 2012;50:1645-9.

42. Labruna MB, Whitworth T, Horta MC, Bouyer DH, McBride JW, Pinter A, et al. Rickettsia species infecting Amblyomma cooperi ticks from an area in the state of São Paulo, Brazil, where Brazilian spotted fever is endemic. J Clin Microbiol. 2004:42:90-8.

43. Regnery RL, Spruill CL, Plikaytis BD. Genotypic identification of rickettsiae and estimation of intraspecies sequence divergence for portions of two rickettsial genes. J Bacteriol. 1991;173:1576-89.

44. Kumar S, Stecher G, Tamura K. MEGA7: Molecular Evolutionary Genetics Analysis version 7.0 for bigger datasets. Mol Biol Evol. 2016:33:1870-4.

45. Rózsa L, Reiczigel J, Majoros G. Quantifying parasites in samples of hosts. J Parasitol. 2000:86:228-32.

46. Hoogstraal H, Clifford CM, Saito Y, Keirans JE. Ixodes (Partipalpiger) ovatus Neumann, subgen. nov: identity, hosts, ecology, and distribution (Ixodoidea: Ixodidae). J Med Entomol. 1973;10:157-64.

47. Foongladda S, Inthawong D, Kositanont U, Gaywee J. Rickettsia, Ehrlichia, Anaplasma, and Bartonella in ticks and fleas from dogs and cats in Bangkok. Vector Borne Zoonotic Dis. 2011;11:1335-41.

48. Low VL, Prakash BK, Lim YAL, Tan TK, Vinnie-Siow WY, Sofian-Azirun M, et al. Detection of Anaplasmataceae agents and co-infection with other tick-borne protozoa in dogs and Rhipicephalus sanguineus sensu lato ticks. Exp Appl Acarol. 2018;75:429-35.

49. Nguyen VL, Colella V, latta R, Bui KL, Dantas-Torres F, Otranto D. Ticks and associated pathogens from dogs in northern Vietnam. Parasitol Res. 2019;118:139-42.

50. Higuchi S, Simomura S, Yoshida H, Hoshi F, Kawamura S, Yasuda Y. Development of Babesia gibsoni in the hemolymph of the vector tick, Haemaphysalis longicornis. J Vet Med Sci. 1991;53:491-3.

51. Jongejan F, Su B-L, Yang H-J, Berger L, Bevers J, Liu P-C, et al. Molecular evidence for the transovarial passage of Babesia gibsoni in Haemaphysalis 
hystricis (Acari: Ixodidae) ticks from Taiwan: a novel vector for canine babesiosis. Parasit Vectors. 2018;11:134.

52. Abarca K, López J, Acosta-Jamett G, Martínez-Valdebenito C. Rickettsia felis in Rhipicephalus sanguineus from two distant Chilean cities. Vector Borne Zoonotic Dis. 2013;13:607-9.

53. Dall'Agnol B, Souza U, Webster A, Weck B, Stenzel B, Labruna M, et al. "Candidatus Rickettsia asemboensis" in Rhipicephalus sanguineus ticks, Brazil. Acta Trop. 2017;167:18-20.

54. Low VL, Prakash BK, Tan TK, Sofian-Azirun M, Anwar FHK, Vinnie-Siow WY, et al. Pathogens in ectoparasites from free-ranging animals: infection with Rickettsia asembonensis in ticks, and a potentially new species of Dipylidium in fleas and lice. Vet Parasitol. 2017;245:102-5.

55. Brouqui P, Parola P, Fournier PE, Raoult D. Spotted fever rickettsioses in southern and eastern Europe. FEMS Immunol Med Microbiol. 2007:49:2-12.

56. Tsui PY, Tsai KH, Weng MH, Hung YW, Liu YT, Hu KY, et al. Molecular detection and characterization of spotted fever group rickettsiae in Taiwan. Am J Trop Med Hyg. 2007;77:883-90.

57. Parola P, Paddock CD, Socolovschi C, Labruna MB, Mediannikov O, KernifT, et al. Update on tick-borne rickettsioses around the world: a geographic approach. Clin Microbiol Rev. 2013;26:657-702.

58. Hsu YM, Lin CC, Chomel BB, Tsai KH, Wu WJ, Huang CG, et al. Identification of Rickettsia felis in fleas but not ticks on stray cats and dogs and the evidence of Rickettsia rhipicephali only in adult stage of Rhipicephalus sanguineus and Rhipicephalus haemaphysaloides. Comp Immunol Microbiol Infect Dis. 2011;34:513-8.

59. Angelakis E, Mediannikov O, Parola P, Raoult D. Rickettsia felis: the complex journey of an emergent human pathogen. Trends Parasitol. 2016;32:554-64

60. Parola P, Miller RS, McDaniel P, Telford SR 3rd, Rolain JM, Wongsrichanalai $C$, et al. Emerging rickettsioses of the Thai-Myanmar border. Emerg Infect Dis. 2003;9:592-5.

61. Tsai KH, Lu HY, Tsai JJ, Yu SK, Huang JH, Shu PY. Human case of Rickettsia felis infection, Taiwan. Emerg Infect Dis. 2008;14:1970-2.

62. Edouard S, Bhengsri S, Dowell SF, Watt G, Parola P, Raoult D. Two human cases of Rickettsia felis infection, Thailand. Emerg Infect Dis. 2014;20:1780-1.

63. Dittrich S, Phommasone K, Anantatat T, Panyanivong P, Slesak G, Blacksell $\mathrm{SD}$, et al. Rickettsia felis infections and comorbid conditions, Laos, 2003-2011. Emerg Infect Dis. 2014;20:1402-4.

64. Le-Viet N, Le VN, Chung H, Phan DT, Phan QD, Cao TV, et al. Prospective case-control analysis of the aetiologies of acute undifferentiated fever in Vietnam. Emerg Microbes Infect. 2019;8:339-52.

65. Mawuntu AHP, Johar E, Anggraeni R, Feliana F, Bernadus JBB, Safari D, et al. Rickettsia felis identified in two fatal cases of acute meningoencephalitis. PLoS Negl Trop Dis. 2020;14:e0007893.

66. Behar A, McCormick LJ, Perlman SJ. Rickettsia felis infection in a common household insect pest, Liposcelis bostrychophila (Psocoptera: Liposcelidae). Appl Environ Microbiol. 2010;76:2280-5.

67. Parola P. Rickettsia felis: from a rare disease in the USA to a common cause of fever in sub-Saharan Africa. Clin Microbiol Infect. 2011;17:996-1000.

68. Ng-Nguyen D, Hii SF, Hoang MT, Nguyen VT, Rees R, Stenos J, et al. Domestic dogs are mammalian reservoirs for the emerging zoonosis fleaborne spotted fever, caused by Rickettsia felis. Sci Rep. 2020;10:4151.

69. Maina AN, Jiang J, Luce-Fedrow A, St John HK, Farris CM, Richards AL. Worldwide presence and features of flea-borne Rickettsia asembonensis. Front Vet Sci. 2019;5:334.
70. Jiang J, Maina AN, Knobel DL, Cleaveland S, Laudisoit A, Wamburu K, et al. Molecular detection of Rickettsia felis and "Candidatus Rickettsia asemboensis" in fleas from human habitats, Asembo, Kenya. Vector Borne Zoonotic Dis. 2013;13:550-8.

71. Tay ST, Koh FX, Kho KL, Sitam FT. Rickettsial infections in monkeys, Malaysia. Emerg Infect Dis. 2015;21:545.

72. Hii SF, Lawrence AL, Cuttell L, Tynas R, Rani PA, Šlapeta J, et al. Evidence for a specific host-endosymbiont relationship between 'Rickettsia sp. genotype RF2125' and Ctenocephalides felis orientis infesting dogs in India. Parasit Vectors. 2015;8:169.

73. Phoosangwalthong P, Hii SF, Kamyingkird K, Kengradomkij C, Pinyopanuwat N, Chimnoi W, et al. Cats as potential mammalian reservoirs for Rickettsia sp. genotype RF2125 in Bangkok, Thailand. Vet Parasitol Reg Stud Reports. 2018;13:188-92.

74. Kho KL, Koh FX, Singh HK, Zan HA, Kukreja A, Ponnampalavanar S, et al. Spotted fever group rickettsioses and murine typhus in a Malaysian teaching hospital. Am J Trop Med Hyg. 2016;95:765-8.

75. Chomel BB, Kasten RW. Bartonellosis, an increasingly recognized zoonosis. J Appl Microbiol. 2010;109:743-50.

76. Assarasakorn S, Veir JK, Hawley JR, Brewer MM, Morris AK, Hill AE, et al. Prevalence of Bartonella species, hemoplasmas, and Rickettsia felis DNA in blood and fleas of cats in Bangkok, Thailand. Res Vet Sci. 2012;93:1213-6.

77. Tsai YL, Lin CC, Chomel BB, Chuang ST, Tsai KH, Wu WJ, et al. Bartonella infection in shelter cats and dogs and their ectoparasites. Vector Borne Zoonotic Dis. 2011;11:1023-30.

78. Noopetch P, Ponpinit T, Suankratay C. Bartonella henselae infective endocarditis with dissemination: a case report and literature review in Southeast Asia. ID Cases. 2018;13:e00441.

79. Watanabe M, Nakao R, Amin-Babjee SM, Maizatul AM, Youn JH, Qiu Y, et al. Molecular screening for Rickettsia, Anaplasmataceae and Coxiella burnetii in Rhipicephalus sanguineus ticks from Malaysia. Trop Biomed. 2015;32:390-8

80. Feng T-H, Chou C-C, Yeh T-M, Su Y-C, Lu Y-P, Shih W-L, et al. Molecular prevalence of zoonotic pathogens in pet and stray dogs in southern Taiwan. Thai J Vet Med. 2015;45:509-22.

81. Pachirat O, Fournier PE, Pussadhamma B, Taksinachanekij S, Lulitanond $\checkmark$, Baggett $\mathrm{HC}$, et al. The first reported cases of $\mathrm{Q}$ fever endocarditis in Thailand. Infect Dis Rep. 2012;4:e7.

82. René-Martellet M, Minard G, Massot R, Van Tran V, Valiente Moro C, Chabanne L, et al. Bacterial microbiota associated with Rhipicephalus sanguineus (s.l.) ticks from France, Senegal and Arizona. Parasit Vectors. 2017;10:416.

83. Zemtsova GE, Apanaskevich DA, Reeves WK, Hahn M, Snellgrove A, Levin ML. Phylogeography of Rhipicephalus sanguineus sensu lato and its relationships with climatic factors. Exp Appl Acarol. 2016;69:191-203.

84. Moraes-Filho J, Krawczak FS, Costa FB, Soares JF, Labruna MB. Comparative evaluation of the vector competence of four South American populations of the Rhipicephalus sanguineus group for the bacterium Ehrlichia canis, the agent of canine monocytic ehrlichiosis. PLoS ONE. 2015;10:e0139386.

\section{Publisher's Note}

Springer Nature remains neutral with regard to jurisdictional claims in published maps and institutional affiliations. 